\title{
O oitavo dia
}

Luiz Maria Veiga ${ }^{1}$

Este conto é para o professor Antonio Dimas por generosamente oferecer, num curso de Literatura Colonial, a possibilidade de apresentar trabalhos ficcionais para avaliação.

I.

O reverendíssimo padre frei Antonio Ventura, vestido com o hábito negro da ordem de S. Bento, principiou sentado e imóvel, em meio aos índios remadores, a viagem para o engenho de seu amigo Gabriel Soares. Observou, à medida que se deslocavam ao longo da costa, as águas da baía tão serenas, o lugar já de si abrigado dos ventos, apenas refrescado por uma leve brisa que soprava do mar para terra, a superfície das águas pouco menos que um espelho, só alterada pelo avançar da canoa, as duas linhas onduladas e em contínuo movimento abrindo-se para trás e, cada vez mais, afastando-se uma da outra.

Quando enfim se convenceu do quase nenhum balançar da embarcação, resolveu ficar em pé, sem mais apoio que o das próprias pernas, para melhor sentir a fresca brisa marinha no rosto e no pescoço e dar aos olhos um horizonte mais largo, para que eles pudessem alcançar e avistar uma área ainda mais ampla daquele lugar pelo qual se apaixonara, e que era sempre descrito, em seu discurso aos recémchegados à Bahia, como "obra-prima de Deus, o mais esplêndido recanto da Criação".

${ }^{1}$ Mestrando em Estudos Comparados de Literaturas de Língua Portuguesa, FFLCHUSP. Pesquisa: Retrato do colonizador e do colono: a representação da minoria branca em algumas obras de literatura angolana. Ficcionista. Endereço eletrônico: veigaluiz@uol.com.br 
Olhando para o lado das águas, frei Ventura via a lisa superficie entre verde e azul, faiscada de reflexos da luz do sol, que tudo iluminava, quase a ponto de ofuscar, ao mesmo tempo em que aquecia, fazendo descer pelas costas, pelo peito, pelos braços, debaixo do hábito, muitas e abundantes gotas de suor. Mas a brisa marinha, acrescentada pelo deslocamento da canoa, era bastante para esfriar até aquelas descendentes gotas de suor. Também era possivel distinguir os perfis verdes das ilhas, desenhados com nitidez contra o azul do céu, umas mais próximas, outras mais distantes. O lampejo de prata de um peixe rompia as águas como um susto, brilhava por um momento fugaz e logo desaparecia, deixando ao surpreso observador a impressão de ter sido vítima de um pequeno delírio ou de uma aparição.

Olhando para o lado da terra, via-se a branca faixa de areia só interrompida pela barra de algum ribeiro, ou ribeirão, ou até rio maior, que dava passagem a embarcações de muitos e muitos tonéis. Logo depois da faixa branca da areia começavam as inumeráveis tonalidades de verde que as muitas espécies vegetais daquela costa fartavam-se de oferecer aos olhos sempre maravilhados do frei. Em alguns pontos viam-se sedes de engenhos e outras construções erguidas para a indústria de fabricar o açúcar. Em outros lugares da costa podiam também ser apreciados os extensos campos, a perder de vista, onde se erguia a cana-de-açúcar com seus troncos, altos como lanças, envoltos em folhas verdes e aguçadas. Naqueles engenhos, diziam os comerciantes da Bahia, era produzido o melhor açúcar de toda a costa do Brasil. Frei Ventura, quando ouvia dizer isso, ficava sempre um pouco cético e perguntava a si mesmo: que outras coisas haveriam eles de dizer a respeito do produto que buscam mercanciar?

Lembrar-se dos comerciantes da Bahia levou-o a pensar na insistência com que seu amigo, Gabriel Soares, solicitara sua presença no engenho. Primeiro viera um dos índios, em dia de levar colheitas do engenho ao mercado. Depois, por duas vezes, vieram índios com recados de seu amo, mandados à cidade da Bahia com o propósito único dessa missão. Por fim, no passado domingo, enquanto ele abria, 
antes da missa, as Sagradas Escrituras no capitulo inicial do Livro do Gênesis, na passagem que devia ser recitada durante a primeira leitura, havia sido surpreendido pela aparição da própria esposa de Gabriel, dona Ana de Argollo, com mais um recado do marido solicitando a presença do frei no engenho tão depressa quanto ele, frei, pudesse ir. E ao recado do marido ela acrescentara, de sua parte, aquele comentário, quase um apelo, para que fosse, fosse sim, que Gabriel andava meio transtornado, comia mal, muitas vezes nem comia, passava os dias a escrever coisas naquelas folhas de papel que depois guardava com muito cuidado numa capa de couro, e que era mesmo preciso que o reverendíssimo padre fosse, porque Gabriel parecia necessitado de falar com alguém, precisava desabafar, parecia ter algo a mordê-lo por dentro, e, com ela, ah, com ela, ele não se abriria de jeito nenhum.

Aqueles apelos e chamados, os comentários de dona Ana, tudo acabou por acender e aumentar a curiosidade de frei Ventura. Foise, no dia seguinte ao da visita da senhora de engenho, ao abade, e solicitou licença de ir em visita ao engenho de Gabriel Soares de Sousa, apanhar a esmola de alimentos que ele sempre fazia ao muito pobre mosteiro de S. Bento, de que era um dos protetores. Obtida a permissão, mandou recado ao engenho, pedindo a Gabriel enviasse canoa e índios para conduzi-lo, pois estava licenciado e pronto para a viagem e à inteira disposição do amigo e irmão em Cristo.

Distraído com aquelas lembranças, frei Ventura só voltou ao instante presente quando viu os índios manobrando para entrar a barra do rio às margens do qual ficava o engenho para onde se dirigiam. Voltou a sentar-se e cobriu-se com o capuz de seu hábito. Muitas vezes, quando a canoa se aproximava da margem e batia nas raízes aéreas das árvores que ali se erguiam, o choque fazia cair uma chuva de aranhas e de outros bichos, talvez igualmente peçonhentos, sobre os ocupantes da canoa. Por isso frei Ventura ergueu o capuz e cobriu a cabeça: não queria aranhas grandes, negras, com suas patas cobertas de pelos, andando nos seus cabelos, enfiando-se para dentro do seu hábito. 
II.

Sobre a grande mesa de madeira maciça, plantada no canto da varanda que rodeava a frente da casa grande do engenho, estavam algumas folhas de papel espalhadas, uma capa de couro, como de livro, fechada, um reservatório meado de tinta, algumas penas repousando dentro de meia cabaça cortada longitudinalmente, uma pena solitária, ainda úmida, largada sobre uma folha meio escrita, onde fazia aumentar uma redonda e por agora ainda minúscula mancha escura. Havia um cadeirão, também de sólida madeira, forrado no assento e no encosto com couro castanho de boi, mas seu ocupante estava por demais inquieto com as ideias que lhe vinham à cabeça, agitado a ponto de não suportar a imobilidade requerida pelo trabalho de escrever por mais que alguns instantes. Coçando as fartas barbas que lhe encobriam o rosto, andando para um lado e para o outro, o homem inquieto e agitado parou num dos ângulos da varanda, agarrou-se à trave de madeira que sustentava o canto do telhado e gritou para um negro, que passava diante do casarão e vinha do lado da margem:

- Ainda não se vê a canoa trazendo o frei? Vai lá até o cais e olha se já estão subindo o rio.

O negro ergueu os olhos para o homem que falava:

- Agora mesmo de lá vim. Não vi nada subindo o rio, senhor Gabriel.

- Pois torna lá e fica vigiando. Assim que avistares algum movimento, anda cá depressa a avisar-me.

O escravo obedeceu depressa e de boa vontade as ordens recebidas. Preferia bem o trabalho de ficar sentado à margem do rio com os pés dentro da água, ao trabalho de ir e vir carregando barris de açúcar para armazená-los no trapiche, à espera de seguirem até a Bahia. O senhor do engenho voltou a seu assento, apanhou entre os dedos a pena esquecida, mas não traçou nenhum risco sobre o papel, tornou a erguer-se e, com as mãos atrás das costas, atravessava com passos largos toda a extensão do soalho de madeira da varanda, 
girando nos calcanhares e retornando, quando alcançava os limites. Repetiu essas manobras ainda uma meia dúzia de vezes antes de ser interrompido pelos gritos do negro que corria rumo à sede do engenho.

- Já se vê, senhor! - E o negro fazia uma pausa para respirar. - A canoa, os remadores...

- Viste o frei no meio deles?

- Ainda estão muito longe... Mas pareceu pra mim que estava no meio deles um homem de hábito, e com o capuz negro puxado sobre a cabeça. Há de ser ele, frei Ventura, há de ser ele!

Gabriel, sem querer ouvir mais nada, desceu aos saltos os cinco degraus que separavam a área do terreiro do soalho de madeira da varanda. Correu, com as pernas que tinha mais as que já tivera, para a beira do rio, olhando sempre a favor da corrente, esperando avistar a embarcação e os remadores. E logo, lá vinham. Mais um tempo e já era possível dizer com certeza que, entre os índios que remavam, vinha o reverendíssimo padre frei Antonio Ventura, a quem o dono daquelas terras esperava com ansiedade, com quem necessitava tanto abrir sua alma, e falar, falar, falar, de tudo que já não the cabia mais no pensamento.

III.

O frei, ainda antes que a canoa acabasse de encostar, ouviu Gabriel Soares, da beira do cais, onde estava em pé, atirar sua saudação:

- Louvado seja Nosso Senhor Jesus Cristo! E que também ele vos dê muitos bons dias, reverendíssimo frei Ventura!

O beneditino, pondo-se em pé, depois de descobrir a cabeça, aceitou a mão que lhe era estendida para melhor se equilibrar e, com um passo grande, pôs-se fora da canoa, firmando-se e reacostumando-se depressa a um chão que não balançava. Só então respondeu à saudação recebida. 
- Para sempre seja louvado, senhor Gabriel Soares, para sempre seja louvado. Aqui estou, enfim, ao seu dispor, para atender a tantos chamados que me mandou Vossa Senhoria. Era preciso atender o homem mais curioso e interessado em todas coisas que jamais houve em toda a costa e sertão desta província. E afinal, que era que queria de mim?

- Agora que vossa reverendíssima já está aqui, não há pressa. Vamos primeiro ao fogão, ver o que fizeram as negras. Frei Ventura há de querer refrescar-se e comer alguma coisa. Depois falaremos das outras coisas.

- Por certo que sim, que quero beber e comer alguma coisa, mas não sei se prefiro antes que o amigo me mate a curiosidade e me diga qual o assunto que tanto o aflige e que me fez vir aqui.

- Vossa reverendíssima havia mesmo de vir de qualquer modo, para apanhar os mantimentos do mosteiro.

- Mas isso era só no próximo mês.

- Vamos, vamos à cozinha. Depois falaremos disso.

Os dois homens, enquanto falavam, davam lentos passos, afastando-se do cais. Os índios descarregaram e amarraram a canoa, levaram a pouca bagagem do frei para a casa de hóspedes e foram tratar das suas outras tarefas.

IV.

Alimentado, refeito e descansado, frei Ventura deixou-se levar por Gabriel Soares para um outro terreiro, mais distante da casa grande, lugar onde ficava reunida a criação doméstica: galinhas, porcos, cabras. Dizia o anfitrião que só the poderia expor as questões que o afligiam depois que o frei visse umas tantas coisas que ele lhe havia de mostrar e que estavam naqueloutro terreiro. Depois de lhe ter sido garantido que a distância do passeio não era grande e que não teriam de atravessar nenhuma extensão de mata, o frei, que tinha muito medo 
às cobras, lá seguiu, atrás do perguntador, o colecionador de espécies, o observador e amador da assim chamada naturaleza.

O frei logo comprovou que a distância era mesmo curta. Passaram por capoeiras repletas de galinhas, por porcos que fossavam em seus chiqueiros, por cabras reunidas em currais, por índios e negros ocupados nos tratos e cuidados da criação, que continuavam suas tarefas como se nem vissem passar por ali o amo deles todos mais o frei. $\mathrm{E}$ os dois foram até um extremo distante, já próximo da boca do mato, mais desocupado e ermo que o restante daquela área.

Gabriel Soares parou diante de uma espécie de jaula de madeira erguida sobre altos pés até a altura de um homem. Dentro dela havia um animal do tamanho de um leitão novo. Como o bicho estava na sombra, frei Ventura não conseguia ver muito bem o que era, ou como era. O dono do engenho, percebendo que o outro fitava a medo e por cima do seu ombro, deu um passo para o lado e mandou que o frei se aproximasse.

- Olhe-me bem para esse bicho, frei Ventura. Sabe o que é? Já tinha visto um?

O beneditino chegou mais perto e espiou para dentro da jaula. Viu que se o corpo do animal lembrava o de um leitão, sua cabeça, e especialmente seu focinho pontudo, afilado, era muito diferente do focinho redondo e chato que têm os porcos. Mas o que mais chamava a atenção no animal era o casco que o envolvia, que lhe cobria todo o corpo, e também o focinho, e as patas. Frei Ventura rodeou a jaula e viu que o bicho, sempre imóvel na sombra, também tinha a cauda igualmente coberta como todo resto dele.

- Este é o animal a que chamam tatu, quer me parecer. Já tive notícia deste bicho, mas nunca tinha visto nenhum. Que é aquilo que ele tem e que lhe cobre todo o corpo?

- É uma armadura, reverendíssimo frei, tão bem articulada e fechada como nunca a tiveram algum daqueles nobres cavaleiros como Amadis de Gaula, ou Tirant lo Blanc, cujas aventuras e maravilhas andam contadas pelos livros. Quando o bicho quer proteger- 
se de um inimigo, mete-se todo para dentro de seu casco. Há outros semelhantes, um pouco menores, que na iminência de um ataque, enrolam-se inteiros em volta de si mesmos, formando uma perfeita esfera, toda feita da mesma casca, e, por mais que queira, não há por onde lhe chegue o inimigo o dente.

- Outro prodígio desta terra tão cheia de prodígios...

- Assim como o vê, não pode vossa reverendíssima admirar-lhe as unhas, que são curvas e fortes como pás, com as quais cava largas e longas tocas dentro da terra, onde vive, e os índios, quando os querem dali desalojar, padecem grandes trabalhos.

- Pois para evitar de os padecer, é deixar quietos os bichinhos, as criaturinhas de Deus, em seus buracos, que me parece que lá de dentro mal não fazem nenhum, aos cristãos ou aos gentios.

Gabriel Soares sorriu francamente, olhando muito para o rosto do beneditino. Depois falou: - Mal não fazem nenhum, tem vossa reverendíssima razão. Não é pelo mal, mas pelo bem que lhes pode fazer, que andam os índios assim com tantos trabalhos atrás de agarrar quantos tatus possam. É pelo bem, e pelo bom, e pelo gosto que tem de os comer cozidos ou assados, pois a carne desses bichos é por eles muito apreciada. E posso dizer a vossa reverendíssima que é apreciada com razão, pois eu mesmo já dela provei e a encontrei de fato muito saborosa.

Diante do silêncio do frade, que seguia olhando cheio de interesse para o animal, tão gabado por seu paladar superior, o dono do engenho continuou: - Estou sempre a pedir que me tragam vivo algum tatu que agarrem, para melhor observá-lo e ver como é feito, mas se mo trazem algumas vezes, como agora, nunca fico muito tempo com ele. Logo alguém, no meio da noite, resolve que aquele tatu melhor estaria assado e comido como refeição, e lá se me vai o bicho. Só lhe encontro o casco, algumas vezes, largado por aí. Já ameacei com reprimendas e castigos, não se comovem. Preferem pagar a carne do bicho com algumas chibatadas na própria carne. 
Gabriel Soares apanhou o frade pelo braço e puxou-o com suavidade, afastando-se com ele do tatu preso na jaula.

- Há mais para ver, reverendíssimo frade, venha comigo, se faz vossemecê favor, com sua licença.

Passaram por uma outra jaula de madeira, circular, onde estava deitado um animal do tamanho de um cão pequeno, ou de uma raposa, mas como estava todo coberto por sua cauda cheia de pelos e dormia, e ressonava, parecia uma almofada, ou um monte de lã, pouco dele se via, e não se detiveram para melhor observar. Ainda assim Gabriel Soares deu notícia ao frade de qual alimária era aquela.

- Chamam-lhe os índios tamanduá, e é bicho que tem como focinho um bico longo, mas não como de ave, e dentro dele uma lingua redonda e comprida que lhe serve muito a contento para recolher aquilo de que se alimenta.

Como o homem se pusesse em seguida calado e nada mais dissesse sobre o assunto, o frade foi obrigado, enquanto caminhavam, a perguntar:

- E, afinal, o que é que comem esses bichos?

Depois de mais uma pausa, Gabriel Soares respondeu: Comem formigas, saiba vossa reverendíssima. Deitam-se como mortos ao pé dum formigueiro, deixam a tal lingua redonda e comprida fora do focinho, pousada sobre a terra, e esperam que as formigas, curiosas e interessadas naquela coisa, reúnam-se em cima dela, e quando a sente bem carregada, puxam-na para dentro, com as formigas todas nela pegadas.

Iam em mais notícias sobre tamanduás e também sobre bichos outros quando chegaram a uma área onde estavam duas ou três árvores isoladas, pouco distantes da mata fechada, limite do terreiro.

- Mas não foi pelo tatu, ou pelo tamanduá, que fiz tanta questão que viesse cá vossa reverendíssima. Foi por causa do bicho que vos vou agora mostrar, e que é talvez a coisa mais espantosa entre tantas coisas espantosas que há cá nesta terra de milagres e espantos. 
O frade beneditino olhou em volta à procura da jaula onde estaria abrigado esse animal. Mas viu que não havia, por ali, nada que se assemelhasse a jaula, ou caixa, ou depósito, ou abrigo. Nada havia por ali que houvesse sido feito pelo homem. Só havia coisas da obra da natureza. Frei Ventura olhou para Gabriel Soares como quem pergunta: onde está?

- Ali, agarrado àquele tronco de árvore.

O frade olhou para o lugar indicado pela mão direita do outro e viu. Lá estava, era verdade, um bicho, à primeira vista uma espécie de macaco, preso com as mãos e os pés ao tronco da árvore, o corpo inteiro encostado a ela. Mas não era um macaco, não podia ser um macaco, alguma coisa estava errada. Toda a experiência que frei Ventura tinha com macacos e bugios lhe dizia que não havia macaco nenhum no mundo capaz de se manter naquela imobilidade agarrado ao tronco de uma árvore. Pelo contrário, raro era o momento em que qualquer daquela espécie parasse de mexer. Agora o bicho parecia ter se resolvido a quebrar aquela sua imobilidade. Despegara uma das mãos do tronco e a estendia, movendo-a mui lentamente, até um outro ponto da casca da árvore, mais acima, onde tornou a se pegar. Frei Ventura ficou com os olhos pregados nele, mas não houve, nos minutos seguintes, mais nenhum outro gesto por parte do animal.

- Que é aquilo?

Gabriel Soares convidou o frade a chegar mais perto. Visto assim, em maior detalhe, era certo que aquele bicho não tinha as proporções dos macacos: seus braços e pernas eram muito compridos e finos, cobertos de pelos longos, tufos, emaranhados de pelos. A cabeça era redonda e também coberta de pelos, que lhe escondiam os olhos. Tinha, nas mãos e nos pés, unhas longas e curvas, muito fortes, e era com elas que ele se mantinha agarrado ao tronco da árvore.

- Isto, frei Ventura, é o bicho que os índios chamam aí e a quem os portugueses crismaram como preguiça, que é nome muito justo e adequado para significar exatamente o que é este animal. Viu vossa reverendíssima com que morosidade a criatura mudou a mão 
para mais acima, no tronco que está a subir. Depois de uma boa pausa, vai mover a outra mão. Depois um pé, o outro pé. E assim, nessa velocidade, leva um dia inteiro para subir, do chão ao alto dos galhos, onde quer se abrigar. É nessa velocidade que ele passa toda sua vida. Não há nada no mundo que o faça mover-se mais depressa. Nem a água subindo, nem o fogo ardendo, nem os cães lhe ladrando, nem as urgências da fome. Não se move, não se pode mover mais depressa, não se quer mover mais depressa, quem há de dizer?

O frade tocou a medo, com uma ponta de dedo, no pelo da criatura.

- É perigoso? Ataca a gente? Morde? Arrebunha com aquelas unhas?

- Nada. É criatura que nunca arremete contra um inimigo. É a criatura mais pacifica, indefesa, desamparada e abandonada que há em toda parte.

- E também são boas para comer, como os tatus? Esses bichos-preguiças são, por certo, bem mais fáceis de agarrar que os tatus.

- Pois talvez seja esta a defesa deles, reverendíssimo frei. Os indios não lhe comem nunca a carne porque tem-lhe nojo. E os preguiças, parece que também não gostam dos indios, talvez também lhes tenham nojo, pois já me disseram estes que esses tais bichos, quando levados a uma aldeia, para junto dos homens, nada comem do que lhes dêem e deixam-se morrer se não forem de novo levados e deixados na mata.

Ainda ficaram por ali uma meia hora, falando de preguiças, e abacaxis, e mandiocas, e outras plantas e bichos que não havia em nenhuma outra parte do mundo a não ser ali. Depois, por não ter mais o que the mostrar que ainda valesse a pena, Gabriel Soares convidou frei Ventura a retornar à casa-grande para que enfim, pudessem conversar. 
V.

- Eis o que me ocorreu, frei Ventura, e que não me sai da cabeça, e que virou na minha vida um ardor que não descansa. Precisava falar com alguém de mais virtude, de mais saber, de mais conhecimento da religião e da vontade de Deus, que me orientasse, que me dissesse se tenho ou não tenho razão.

- E o que é que vos aflige, meu filho?

Gabriel Soares, que fitava o padre a direito, desviou os olhos, como se ainda tivesse medo de dizer o que ia dizer. Após uma pausa, lá se resolveu. Sem erguer os olhos, disse:

- A ideia de que esta terra, este continente, este novo mundo descoberto, é obra posterior da Criação de Deus, não foi feita ao mesmo tempo em que foi feito o resto do mundo.

O frade, ainda que sentisse um certo espanto diante do que ouvia, nada deixou transparecer no rosto. Ouvia as palavras do seu amigo como se ouvisse uma confissão. Deixou-o falar à sua vontade, quanto e como quisesse.

- Quando vi a criatura chamada preguiça, acabei de me convencer que era isso mesmo, que só podia ser assim. Não há nada que se lhe assemelhe em outras terras onde andaram portugueses e contaram delas as coisas que viram. E os portugueses andaram por toda parte que há. Não há nada como os preguiças, os tatus, os tamanduás. E não há nada como os abacaxis, a mandioca. E muitas outras coisas, essa planta que se chama milho, e esses tubérculos que se chamam batata, e batata doce, e essoutra que os castelhanos chamam tomate, e ainda mais.

O padre frei tudo ouvia, em silêncio, sem mexer um pelo da sobrancelha, sem movimentar um único músculo da face. A barba de Gabriel Soares movia-se sem descanso.

- Se não há notícia dessas coisas nas Sagradas Escrituras, se não há notícias delas nos cosmógrafos e geógrafos clássicos ou modernos, se Aristóteles não fala nelas, nem mais ninguém depois dele, 
é porque tudo isso só foi criado muito depois. Esta terra não foi feita naqueles seis dias de que nos fala o livro do Gênesis. Tampouco foi feito no sétimo, porque sabemos todos que no sétimo dia Deus descansou e nada fez. Então foi no oitavo dia. Foi no oitavo dia, depois de descansar, e porque talvez não tivesse outra coisa a fazer, já que a humanidade ainda não estava espalhada pelo mundo a lhe dar trabalho, resolveu fazer uma terra nova. Pôs nela algumas das coisas que já havia criado nas outras, outras não pôs, mas fez algumas coisas completamente novas, especialmente feitas para estar aqui, neste lugar. São coisas tão novas que fico muitas vezes parado, a pensar, com a pena na mão, com o papel diante de mim, sem saber como hei de reduzir a palavras aquilo que não foi nunca nomeado. Para explicar a vossa reverendíssima o que é um preguiça foi fácil: peguei-vos, com todo respeito, pelo braço, e vos levei até onde ele estava e coloquei-vos diante dele para que pudésseis vê-lo e acreditar nele com o testemunho de vossos próprios olhos. Mas como hei de reduzir, de conformar a palavras que nunca serviram para descrevê-lo, ou para registrar sua existência, esse bicho, essa novidade? Porque é preciso que as palavras sejam capazes de mostrar a quem está lá, do outro lado do mar-oceano, que é e como é esse bicho. Será isso possivel, reverendíssimo padre? E o abacaxi, também dito ananás? Até posso, com muito esforço, servindo-me de comparações e analogias, dar dele uma idéia a alguém que nunca o viu. Mas como hei de reduzir a palavras o sabor, sabe me dizer vossa reverendíssima se tal cousa é possivel?

Gabriel Soares levantou-se do banco em que estivera sentado, deu uma volta pelo aposento cujas portas e janelas estavam fechadas porque já havia anoitecido e era preciso evitar que entrassem todos os insetos. A iluminação vinha de dois ou três candeeiros de óleo de baleia, pendurados em alguns lugares. As sombras do dono da casa se agigantaram contra as paredes, movendo-se em uníssono e harmonia com os movimentos do corpo que imitavam. As sombras imobilizaramse quando o homem parou de repente e ficou em pé diante de frei Ventura, que permanecia sentado e imóvel, impassivel. 
- Então já me lembrou mais de uma vez que esse livro que estou a escrever, com todas essas lembranças e memórias que venho juntando, essa notícia do Brasil que venho compondo, ele também há de ser inspirado por Deus talqualmente os outros, porque é talvez uma espécie de continuação, de capítulo final do Livro do Gênesis... Não será assim, reverendissimo padre frei Ventura?

Embora tivesse vontade de arregalar os olhos e de abrir muito a boca diante daquilo tudo que ouvia, frei Ventura limitou-se a erguer-se, na atitude de quem cansou de estar sempre na mesma posição. E lá ficou em pé, em silêncio, fazendo Gabriel Soares esperar algum tempo pela resposta. Disse, enfim:

- Já é muito tarde, necessito me recolher porque estou cansado e ainda tenho minhas orações para fazer. Quero fazê-las e quero meditar, e quero orar a Deus, e só então me acreditarei preparado para vos dar a resposta que me pedis, meu caro amigo. Creio que ainda agüentareis passar mais uma noite de espera, antes de ouvir meu comentário.

- Creio que agüentarei. É justo que vossa reverendíssima medite em tudo que lhe falei antes de me dar uma resposta. Sei quanto é grave tudo isso em que tenho pensado. Não quero, de modo nenhum, ofender as verdades da nossa santa fé. Mas não consigo deixar de pensar nessas coisas todas.

- Amanhã falaremos. Nosso Senhor lhe dê muito boas noites, senhor Gabriel Soares.

- E que igualmente vos dê o mesmo, reverendíssimo padre frei, além da inspiração e sabedoria que com certeza ireis lhe pedir.

- Amanhã falaremos - tornou a repetir o frade, antes de se retirar do aposento.

VI.

Na manhã seguinte ambos, anfitrião e hóspede, ergueramse cedo. Gabriel Soares tinha os olhos fundos, talvez nem tivesse 
chegado a dormir. Tomaram juntos a primeira refeição, falaram de muitas coisas diferentes, das ameaças dos barcos dos hereges que viviam rondando a Bahia, de como se podia defender a cidade, da quantidade de açúcar que o engenho contava produzir aquele ano, das notícias de minas de ouro e de pedras preciosas que corriam sem ninguém saber exatamente onde é que elas se localizavam, do projeto que tinha Gabriel Soares de ir à Espanha, solicitar ao rei a licença oficial, alguma ajuda e o alvará-régio para se lançar ao sertão, onde esperava encontrar aquelas jazidas de extraordinária riqueza pelas quais tantos viviam e gastavam suas vidas e morriam naquelas terras desconhecidas, ainda por palmilhar e mapear. Da questão levantada na noite anterior, nada falava o frade, e o dono da casa, embora ardesse por saber, acanhava-se de perguntar.

Estando já os remadores a bordo da canoa carregada com os mantimentos que o dono do engenho enviava, a cada três meses, ao mosteiro de S. Bento, e pronta a outra, em que voltaria frei Ventura, em que também iriam seis remadores, e havendo os dois homens brancos notícia disso, ergueram-se para seguir até o cais, onde deveriam despedir-se.

Foi no caminho para o rio que o frei tocou, enfim, no assunto:

- Muito rezei, e meditei, e pedi inspiração a Deus sobre as coisas que me disse o amigo. E não há outra coisa que lhe possa dizer, sem agravo de minha consciência, a não ser isto: afasta-se dessas idéias que anda tendo, que só lhe podem estar sendo inspiradas por Satanás em pessoa, vade retro! Deus criou o mundo e tudo que nele há de uma única vez, em seis dias, conforme está contado na Escritura Sagrada e manda que acreditemos nossa Santa Mãe, a Igreja Católica Apostólica e Romana. Presumir-se alguém de escritor inspirado, de complementador da Escritura, de cronista de uma falsa obra posterior de Deus, é maldade soprada pelo demônio, para avivar o pecado do orgulho no coração e na alma do cristão, cuidando assim das ganâncias do seu interesse, que é entregá-la ao fogo do inferno e à danação eterna. 
Gabriel Soares fazia seguidamente, sinais da cruz na testa, sobre a boca, no peito. Parecia aterrado diante das coisas que ouvia o frade beneditino dizer.

- E além da perdição eterna de vossa alma, o amigo ainda corre o risco, se persiste em repetir tudo isso que me disse, nessa viagem que pretende fazer a Madrid, de ser levado aos cárceres e aos tratos que dá a Inquisição a seus prisioneiros, além do risco de ir parar à fogueira do auto-de-fé, ainda antes de experimentar os fogos eternos das profundezas infernais.

Gabriel Soares não queria ouvir mais nada. Interrompeu frei Ventura aos gritos:

- Renuncio, renuncio a tudo que pensei, não quero escrever mais nada, vou atirar fora tudo que já fiz, não quero, tenho medo de perder minha alma. Nunca mais torno a repetir, e desde agora descreio completamente, em tudo que disse à vossa reverendíssima na noite de ontem.

Já haviam chegado à beira do cais. Os índios andavam para lá e para cá, ajeitando o que faltava, amarrando melhor um balaio com galinhas vivas, aguardando as ordens, alerta para elas, sem ouvir mais nada do que diziam o senhor e o frade da Bahia. Falassem eles alto ou baixo, como agora falava o amo, pouco lhes importava. Prestavam atenção só à espera de que, por fim, lhes falassem. Só então ouviriam e responderiam fazendo o que lhes fosse ordenado.

- Não é o caso, meu caro amigo Gabriel Soares, de destruir todo esse belo trabalho de informação que vindes colecionando desde tanto tempo. Basta que vos ocupeis apenas em contar as maravilhas que nós, criaturas de Deus, encontramos nesta terra igualmente criada por sua divina mão. Basta que informeis aos que estão longe daqui, que Deus não se cansou nunca de criar surpreendentes maravilhas, e que fez tantas, e de tal variedade, que nós homens ainda temos muito que andar, e estudar, e saber, e descobrir, antes de conhecermos toda a extensão da obra do nosso Criador. Nisso não há heresia, nem pecado, é um trabalho de grande mérito e que será, com certeza, visto com 
benevolência por Jesus Cristo, nosso Salvador, a quem está dedicada a cidade da Bahia. Não atireis fora vosso trabalho que ele ainda há de dar grande notícia e informação a todos que quiseram saber mais sobre esta terra de prodígios.

- Sem risco de que eu venha a perder a minha alma?

- Se vos ocupardes, senhor, em descrever as coisas desta terra, sejam elas prodigiosas, sejam elas terriveis, e tiverdes como guia apenas a verdade, não há risco para vossa alma.

- As coisas terriveis desta terra? E que coisas seriam essas, reverendíssimo frei?

- Ora, não dedicareis um capítulo ao menos, do vosso escrito, a contar esse bárbaro costume que têm os tupinambás de devorarem os seus adversários vencidos na guerra? Criaturas de Deus assando e comendo criaturas de Deus como quem assa e come um leitão ou um cabrito, não será isso uma das coisas mais terriveis de que já se teve notícia em qualquer tempo? Adeus, adeus, senhor Gabriel Soares. Ficai com Nosso Senhor e com os anjos, e deixai de idéias e de novidades. Deus fez o mundo todo de uma vez só, disso não vos olvideis. O resto é desocupação e mentira, soprada na cabeça do homem pelas ventas malévolas do diabo, livre-nos Nossa Senhora sempre de sua peçonha!

Agilmente o frei subiu para a canoa e assentou-se sobre a travessa de madeira que havia no centro dela. Os indios remadores estavam em seus lugares e tinham seus instrumentos de oficio nas mãos.

- Dai as ordens para que partamos, senhor Gabriel. Quero chegar à Bahia ainda a tempo de rezar as vésperas.

O dono do engenho tinha uma nova preocupação:

- Vossa reverendíssima acredita que estas minhas ideias hão de me custar alguma temporada grande no Purgatório?

- Talvez, senhor Gabriel, talvez. Mas agarrai-vos com a Santa Madre de Deus, a advogada capaz de tirar das terriveis e dolorosas chamas purificadoras as almas dos pecadores ainda antes 
que tenham cumprido todo o tempo de suas penas. Dizei aos vossos indios que é preciso partir, senhor Gabriel, que se vai fazendo mui tarde.

Gabriel Soares de Sousa ordenou a seus índios que largassem, seguissem rumo à cidade da Bahia e que lá deixassem o padre frei Ventura, e que não se esquecessem de trazer dona Ana, que estava à espera deles, pois já era tempo de ter concluído os negócios que a levaram à cidade.

O assustado estudioso das coisas do Brasil ficou em pé no cais, olhando as canoas que se afastavam, até que elas sumissem completamente de vista na direção da boca do rio, no rumo do mar. Depois virou as costas para o rio, e seguiu, em passos curtos, lentos, rumo à casa grande.

VII.

Sentado no cadeirão de madeira, diante da mesa da varanda, com o espírito mais sossegado e a alma contrita depois de muitas orações, Gabriel molhou no depósito de tinta a pena que tinha na mão e a levou até a folha onde vinha redigindo seu testamento e acrescentou-1he, com grande alivio, lenta e diligentemente, letra por letra, palavra por palavra, linha por linha, um novo parágrafo, juntado às recomendações que já lá estavam, sobre as providências que deviam ser tomadas para garantir, com toda certeza possivel, sua salvação eterna:

Nos outros cinco dias seguintes, se dirão em cada dia outras dez missas rezadas e uma cantada à honra dos cinco mistérios gloriosos da Virgem Madre de Deus. E se não houver padres no dito mosteiro de $S$. Bento que bastem para dizerem estas missas juntas, humildemente peço ao padre abade que ordene com os padres do colégio ou da Sé, com que se possam dizer estas missas como tenho declarado, porque tenho confiança na Madre de Deus que, ao cabo destas missas, sairá minha alma do Purgatório. 


\section{REFERÊNCIAS BIBLIOGRÁFICAS}

SOUSA, Gabriel Soares de. Tratado descritivo do Brasil em 1857. São

Paulo:Companhia Editora Nacional/Editora da Universidade de São Paulo, 1971.

SOUZA, Laura de Mello e (org.). História da vida privada no Brasil: cotidiano e vida privada na América Portuguesa, V. 1. São Paulo, Companhia das Letras, 1997.

VARNHAGEN, Francisco Adolfo de. História geral do Brasil antes da sua separação e independência de Portugal, tomo primeiro. São Paulo: Melhoramentos, 1956.

História geral do Brasil antes da sua separação e independência de Portugal, tomo segundo. São Paulo: Melhoramentos, 1956. 